Research Article

\title{
Prevalence and Determinants of Diarrhea among Under-Five Children in Benna Tsemay District, South Omo Zone, Southern Ethiopia: A Community-Based Cross-Sectional Study in Pastoralist and Agropastoralist Context
}

\author{
Mulusew Alemayehu, ${ }^{1}$ Tsegaye Alemu $\mathbb{D}^{2},{ }^{2}$ and Ayalew Astatkie $\mathbb{D}^{3}$ \\ ${ }^{1}$ South Omo Zone Health Department, Jinka 20, Ethiopia \\ ${ }^{2}$ Maternal and Child Health Department, JSI/L10K Project, Hawassa 1968, Ethiopia \\ ${ }^{3}$ School of Public Health, College of Medicine and Health Sciences, Hawassa University, Hawassa 1560, Ethiopia \\ Correspondence should be addressed to Tsegaye Alemu; tsegayea49@gmail.com
}

Received 4 November 2019; Revised 30 April 2020; Accepted 18 May 2020; Published 1 June 2020

Academic Editor: Carol J. Burns

Copyright (c) 2020 Mulusew Alemayehu et al. This is an open access article distributed under the Creative Commons Attribution License, which permits unrestricted use, distribution, and reproduction in any medium, provided the original work is properly cited.

\begin{abstract}
Background. Diarrhea is the second leading cause of death among children under-five years globally and accounts for about 1.5 million deaths each year. In low-income countries, children under three years of age experience three episodes of diarrhea on average every year. In Ethiopia, diarrheal disease is one of the common causes of mortality in under-five children. In Benna Tsemay district, pastoralist community lives with lack of clean water, sanitation, and hygiene problems, which increase the risk of childhood diarrhea. Objective. To assess the prevalence and determinant of diarrheal disease among under five children in Benna Tsemay District, South Omo Zone, Southern Ethiopia. Methods. A community-based cross-sectional study was conducted on a sample of 722 under five children selected randomly from eight pastoralists and two agropastoralist kebels. Data were collected using an interviewer-administered questionnaire. Data were analyzed using the Statistical Package for Social Sciences (SPSS) version 20. Logic regression was performed to identify the association between diarrheal disease and independent variables. Adjusted odds ratio with $95 \%$ confidence intervals (CIs) was used to judge the presence of association. Results. The two-week period prevalence of childhood diarrheal disease in the study was $23.5 \%$ ( $95 \%$ CI: 20.4\%-26.6\%). Diarrheal illness was associated with nonavailability of latrine (AOR: 2.77, 95\% CI: 1.66-4.63), faeces seen around the pit hole or floor of latrine (AOR: 2.92, 95\% CI: 1.38-6.19), improper kitchen waste disposal (AOR: 2.31, 95\% CI: 1.26-4. 24), unprotected drinking water source (AOR: 1.81, 95\% CI: 1.14-2.88), mother's or caretaker's diarrhea history in the last two weeks (AOR: 6.74, 95\% CI: 2.51-18.07), materials used for feeding the child (cup and spoon) (AOR: 0.60, 95\% CI: 0.36-0.97), and being unvaccinated for "rotavirus" (AOR: 2.87, 95\% CI: 1.86-4.44). Conclusion. Nearly one-fourth of children had diarrheal illness in the preceding two weeks. Water, sanitation and hygiene-related factors, child feeding practice, and children's vaccination status for rotavirus were the determinants of the occurrence of diarrhea among under-five children. The health office should conduct sustainable health education programs that emphasize on risk of open defecation, waste disposal mechanisms, and child feeding practices and also should strengthen rotavirus vaccination activities. The district administration and partners' needed to improve water sources.
\end{abstract}

\section{Introduction}

Diarrhea can be defined as experiencing loose or watery stool for three or more times during a 24 -hour period. It is caused mostly by infection causing pathogens including bacteria, viruses, and parasites [1]. Infectious diarrhea is acquired by fecal-oral transmission route, by person to person contact, through water or food or directly to the mouth. The absence of a proper water supply, with rubbish and dirty surroundings and an abundance of flies, is the typical situation in which diarrheal diseases are transmitted [2]. 
Diarrhea is a major public health problem. It is the second leading cause of death among children under-five years globally and accounts for almost one in five child deaths, about 1.5 million each year. Cumulatively, it alone kills more young children than acquired immune deficiency syndrome (AIDS), malaria, and measles [3].The majority of this death is in children who live in low- and middle-income countries [4].

United Nations Children's Fund's (UNICEF's) 2016 report indicates that diarrheal disease accounts for approximately 8 percent of all deaths among children under the age of five years worldwide. This means that over 1,300 young children die each day, or about 480,000 children in a year, despite the availability of simple effective treatment [5]. In low-income countries, children under three years old experience on average three episodes of diarrhea every year. In each episode, the child loses nutrition that is necessary for growth. As a result, diarrhea becomes a serious cause of malnutrition and the malnourished children are more likely to fall ill from diarrhea [6]. However, in developed countries, relatively few patients die from diarrhea, because the morbidity from diarrheal diseases has remained relatively constant during the past two decades. Studies conducted in central and rural Ethiopia have revealed diarrheal disease to be one of the common causes of under-five mortality, accounting for approximately $8.4 \%$ to $27 \%$ of all deaths [7].

Intervention is required to prevent diarrhea which includes providing safe drinking water, use of improved sanitations, and hand washing with soap. Diarrhea can also be treated with oral rehydration solution (ORS) or a solution of clean water, sugar, and salt. In addition, a 10-14 days supplemental treatment course of $20 \mathrm{mg}$ zinc tablets shortens diarrhea disease duration and improves outcomes [6].

The magnitude of childhood diarrhea differ from one region to the other. According to the 2016 Ethiopian Demographic and Health Survey (EDHS) report, the two-week period prevalence of diarrhea among under- five children was approximately $12 \%$ [8], but a study conducted in northwestern Ethiopia showed the two weeks period prevalence of diarrhea among under-five children in 2017 to be $20 \%$. Similarly, a community-based cross-sectional study conducted in Jabitehnan district, West Gojjam Zone, Amhara Region, Ethiopia, reported a 21.5\% two-week period prevalence of diarrhea $[9,10]$. But in most remote and pastoralist areas, the prevalence is expected to be higher because of shortage of drinking water, poor sanitation, and low educational and awareness levels. For example, a study in Somali Region, Eastern Ethiopia (a predominantly pastoralist area), has shown the two-week period prevalence of diarrhea among under-five children to be more than two times that of the national prevalence [11].

Benna Tsemaye District is one of a pastoralist districts in the South Omo Zone of Southern Ethiopia. According to the District Health Office 2016/17 report, 28.5\% of all under five outpatient department visits in the district were due to diarrheal diseases and diarrheal disease was the first leading cause of morbidity in the district. Having low access to improved drinking water sources and obtaining water from unprotected water sources such as rivers or ponds put children in the district at a higher risk of diarrheal diseases.

However, there is no study which documented on the prevalence and determinant factors associated with diarrheal disease in Benna Tsemay District. Therefore, the aim of this study was to identify the prevalence and determinants of diarrheal disease among children younger than five years in the district. The information may be used to design locally applicable interventions in accordance with the identified determinants of childhood diarrhea.

\section{Materials and Methods}

2.1. Study Area. Benna Tsemay District is one of the districts in the South Omo Zone of southern Ethiopia. The capital of the district is Keyafer, which is located $483 \mathrm{kms}$ and $708 \mathrm{kms}$ to south from the regional capital Hawassa and Addis Ababa, respectively, and $42 \mathrm{kms}$ away from Jinka, the capital of South Omo Zone. It is bordered, in the south by Hammer District, in the west by Salamago, in the north by South Aari and Maale Districts, in the northeast by the Segen Zone, and in the south east by the Oromia Region. The Woito River separates it from Segen Zone and Oromia Region. The western part of the district is part of the Mago National Park (Figure 1). The estimated population size in Benna Tsemay District in 2016/ 17 was 68,774 (that means $9.2 \%$ of the total population of South Omo Zone); from these, 34,524 (50.19\%) were females. The total number of households in the district is 14,035 . Children under five years of age are 10,736 and approximately $58,458(85 \%)$ of the population resides in rural kebeles (the smallest administrative units in Ethiopia [12].

The district has a total of 32 kebeles of which 28 are pastoralists and the remaining four are agropastoralists. The district currently has 6 health centers and 32 health posts. It has predominantly hot and humid climatic condition with $400-1400 \mathrm{~mm}^{3}$ annual average rainfall and $23^{\circ} \mathrm{C}$ average monthly temperature. The majority of the population is pastoralist. According the district mine and water office report, in 2016/2017, the main water sources for the majority of the populations were shallow well fitted with hand pump and pool water[13].

2.2. Study Design and Population. A community-based cross-sectional study was conducted from 01 January to 30 February, 2019, among children under five years of age who were living in Benna Tsemay District, southern Ethiopia. The study population comprised of children under five years old found in selected kebeles and selected households.

\subsection{Sample Size Determination and Sampling Procedures.} The sample size required for determining the prevalence of diarrhea was calculated using a single population proportion formula by considering the prevalence of under-five diarrheal disease as $30.5 \%$ [14]. The researchers considered $5 \%$ of margin of error, and 95\% confidence level. The calculated sample size was 326. Taking a design effect of 2 and by adding $10 \%$ for nonrespondence, the final calculated sample size was 717 . The sample size required to identify the 

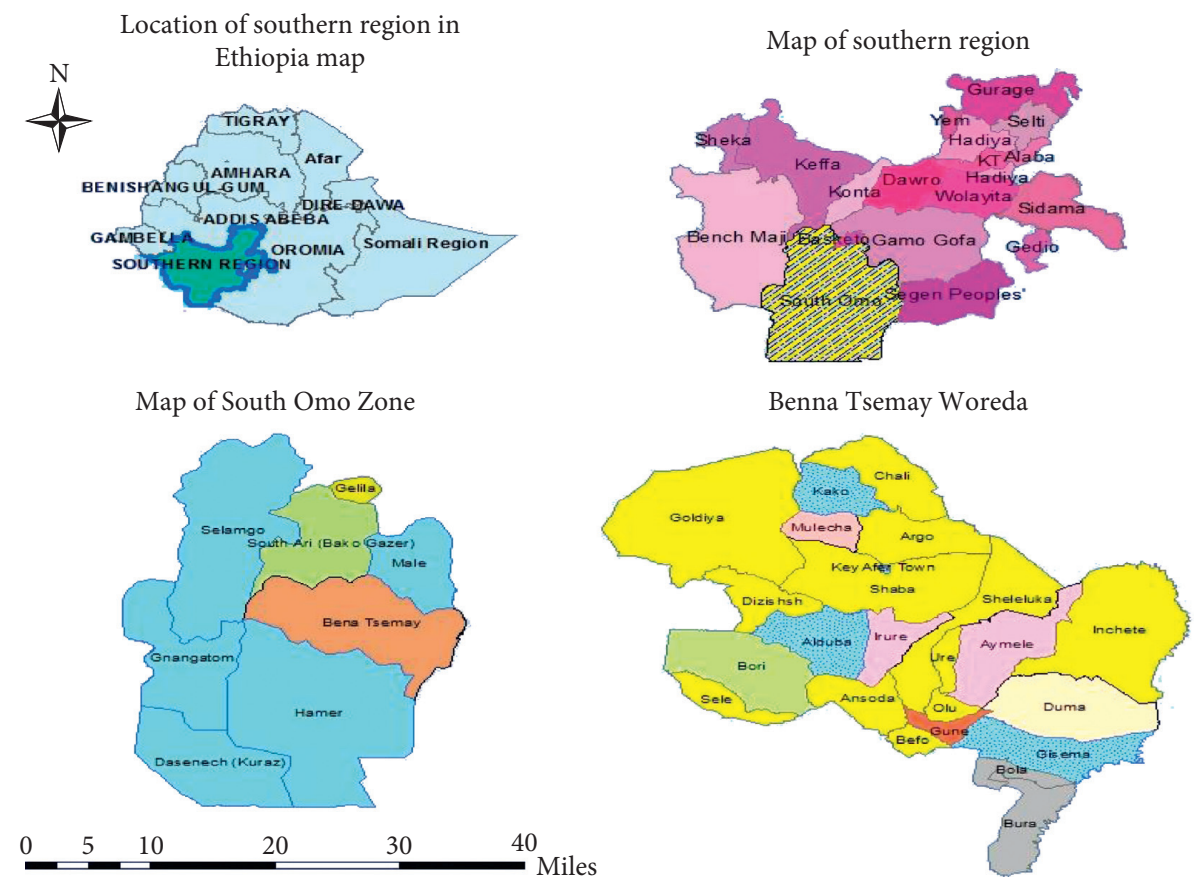

Figure 1: Administrative map of Benna Tsemay Woreda, South Omo Zone, Southern Ethiopia, 2019.

determinants of diarrhea was calculated by using Epi info Version 7. By taking the proportion of children who are from households with improved water sources to be $27.35 \%$ and the odds ratio of unimproved water source vs improved water sources to be 1.98 based on a study in Gamo Goffa Zone, Arba-minch District [14] and considering a confidence level of $95 \%$, a power of $80 \%$, and an unexposed-toexposed ratio of 1 , the sample size calculated was 722 . As the sample size for objective two (722) is larger than the sample size for the first objective (717), we used the maximum sample size of 722 for the study.

Multistage sampling technique was used to select the households. In Benna Tsemay District, there are 28 pastoralist and 4 agropastoralist kebeles. According to the rule of thumb for the feasibility of the study, about $31 \%$ of Kebeles were covered by this study. Among them, eight pastoralist and two agropastoralist Kebeles were randomly selected. The kebeles were stratified as pastoralist and agropastoralist kebeles. All of the kebeles in each stratum were listed alphabetically, and then a simple random sampling technique was used to select the specific kebeles for this study. Finally, systematic sampling technique was employed to select households with $4^{\text {th }}$ interval and under-five children in the selected households were included in the study. If the selected household had two or more children less than five years of age, one child was selected randomly.

2.4. Data Collection Tools and Procedures. Data were collected from 01 January to 30 February, 2019, using structured, pretested, and interviewer-administered questionnaire. The questionnaire was prepared based on the EDHS and other literature which is related to diarrhea among under-five children [1,15-17]. The questionnaire consisted of a total of
59 close-ended questions which were divided into four sections. The first section contained residence of household, number of children under-five and family size; the second section included demographic and economic variables; the third section was about potential predisposing environmental factors, and the fourth section contained information about the index child (including diarrheal morbidity).

The instrument was prepared in English and then translated into Amharic for the data collection. Respondents were mothers of the eligible children, but in the absence of the mother, the next primary caregiver was interviewed. The data were collected by eight data collectors; among these six were grade $10^{\text {th }}$ or grade $12^{\text {th }}$ or university students. Two diploma holder nurses supervised the data collection. The data collectors had experience in data collection in rural communities and were fluent in Amharic. In addition, they can speak Bennigna and Tsemayigna languages (the local languages of the study area). Moreover, two Ethiopian field epidemiology and laboratory training program residents provided overall oversight in the data collection process.

2.5. Data Quality Assurance. Training and discussion on contents of the questionnaire, methods of interview with local language, and important factual data for three days were conducted for all data collectors and supervisors prior to starting the data collection. The questionnaire was pretested in sample kebles that were not included in the main survey. Proper and close supervision of the interviewers was done to ensure accuracy and to help clarify any issues that arise in the data collection process. The investigator checked the filled questionnaires carefully for completeness and any missing responses at the end of the day and feedback was given to the data collectors for correction the following day. 
2.6. Data Analysis. Responses were properly coded before being entered into a computer program. Data entry and analysis were performed using SPSS version 20, and the results were summarized using tables. For continuous variables, normality of the distribution was assessed based on histogram with a distribution curve. Multiple logistic regression was fitted using the "enter" method to identify the determinants of diarrhea adjusting the effect of each variable for the confounding effect of other variables in the model. Variables entered into the multivariate model were those having $P \leq 0.25$ in the bivariable regression. The fitness of the model was assessed using Hosmer-Lemeshow statistic. Finally, the outputs of bivariable and multivariable logistic regression were presented, respectively, as crude odds ratio (COR) and adjusted odds ratio (AOR) along with their 95\% confidence interval (CI). The AORs with their 95\% CIs were used to assess the presence and strength of association between diarrheal morbidity and different determinants.

\section{Ethical Considerations}

Ethical clearance was obtained from the Institutional Review Board at the College of Medicine and Health Sciences of Hawassa University. Permission letters were obtained from South Omo Zone Health Department and Benna Tsemay District Health Office. Further, verbal informed consent was obtained from each respondent after clearly explaining the purpose of the study and data confidentiality. The verbal consent was preferred because the majority of the respondents were illiterate. Confidentiality of the information acquired was assured by using only codes and by avoiding use of any personal identifiers. During the interview, mothers or caretakers unable to complete the interview were allowed to withdraw from the interview. For children having active diarrhea during the study, the mothers/care takers were advised to visit the nearby health facility to get treatment for the children with diarrhea.

\section{Results}

4.1. Demographic and Socioeconomic Characteristics of the Households. A total of 722 under-five children with their mothers/caretakers were planned to be included in the study, and all took part in the study resulting in a response rate of $100 \%$. Among the total participants, $521(72.2 \%)$ were rural dwellers and 709 (98.2\%) of the interviews were conducted with biological mothers and the rest with caretakers of the children. More than two-thirds (68.6\%) of the households had a family size of greater than four people.

The mean ( \pm standard deviation (SD)) age of the mothers or caretakers of the children included in the study was 30.5 $( \pm 6.97)$ years and ranged from 18 to 48 years. Majority $(96.7 \%)$ of the mothers or caretakers were married. Almost half of the mothers (49.4\%) were traditional believers by their religion and the majority $(71.7 \%)$ of the mothers or caretakers did not attend any formal education and 310 (42.9\%) were farmers by occupation (Table 1 ).
4.2. Environmental Characteristics of the Households. Of the total households from which the children were selected, the majority (87.4\%) had dwellings with mud floor and 570 (78.9\%) had no roof. One-hundred eighty seven $(25.9 \%)$ households shared their living rooms with animals and 479 $(65.7 \%)$ households had only one room. Four-hundred thirty eight $(60.7 \%)$ of the households had latrine facility, of which $428(97.7 \%)$ were traditional pit type of latrine, $414(94.5 \%)$ had privately owned latrine and $380(86.8 \%)$ were clean, i.e., had no faeces seen around floor of the latrine.

In $91.4 \%$ of the 438 households with latrine facility, the pit holes did not have a cover. In 161 (36.8\%) of the addressed households, flies were seen around house or in toilet area. From the households having latrine, 76 (17.4\%) had hand washing facility at the toilet, of which only half $(51.3 \%, n=39)$ had water during the data collection and only $17(22.4 \%)$ had soap or ash at the handwashing facility.

Four-hundred and thirty eight (60.7\%) of the households used drinking water from protected water sources. The cost of water consumption per month indicated that the majority (86.3\%) of the households were spending less than $\$ 0.5$ per month and 288 (39.9\%) took more than 30-minute walk to fetch water. Further, two-hundred thirty four (32.4\%) of the households use water storage containers, the majority (74.4\%) of which are locally available Jerry cans. From the total households, $129(17.9 \%)$ treat their drinking water at home, of whom 61 (47.7\%) used chemicals to treat the water (Table 2).

4.3. Characteristics of the Index Children. Of the 722 index children, 339 (47\%) were 24 months old and above and 386 $(53.5 \%)$ were females. The mean $( \pm S D)$ age of the index children was $21.42( \pm 13.78)$ months. Regarding the place of delivery, almost two-third (66.9\%) of the children were born in health institutions. In terms of their birth order, 353 (48.9\%) of the children had an order of four and above.

During the data collection period, majority (96.7\%) of the mothers or caregivers responded that they did not have history of diarrhea in the last two weeks. Out of the total 722 mothers or caretakers, 101 (14.2\%) mothers were exclusively breastfeeding their children at the time of the study. Out of those mothers who initiated additional food for their children, 292 (47.7\%) mothers started supplementary feeding for their children before the child reached 6 months.

Regarding type of food or fluid prepared for their children, $41.1 \%$ of the mothers/caregivers were using cow milk and $280(45.1 \%)$ used cup and spoon to feed their children. Besides, about three-quarters (74.6\%) of the mothers/caregivers responded that they prepare food for their children separately from the food for other family members. Concerning the vaccination status of children, 521 (72.2\%) of the children were vaccinated for measles and 466 (64.5\%) were vaccinated for rotavirus.

With regard to the prevalence of diarrheal disease among under-five children, 170 (23.5\%, 95\% CI: 20.4\%-26.6\%) of the children had a diarrheal disease in the two-week period preceding the study (Table 3 ). 
TABle 1: Demographic and socioeconomic characteristics of the households in Benna Tsemay District, South Omo Zone, Southern Ethiopia, 01 January to 30 February, 2019.

\begin{tabular}{|c|c|c|c|}
\hline Variables $(n=722)$ & Response category & Frequency & Percentage $(\%)$ \\
\hline \multirow{2}{*}{ Residence } & Urban & 201 & 27.8 \\
\hline & Rural & 521 & 72.2 \\
\hline \multirow{2}{*}{ Family size } & Four and less & 227 & 31.4 \\
\hline & More than four & 495 & 68.6 \\
\hline \multirow{2}{*}{ Number of under-five children in the household } & One & 314 & 43.5 \\
\hline & Two and above & 408 & 56.6 \\
\hline \multirow{2}{*}{ Relation of respondents to child } & Mother & 709 & 98.2 \\
\hline & Care taker & 13 & 1.8 \\
\hline \multirow{3}{*}{ Age of mothers or caretaker } & $18-24$ & 155 & 21.5 \\
\hline & $25-34$ & 342 & 47.4 \\
\hline & 35 and more & 225 & 31.2 \\
\hline \multirow{3}{*}{ Marital status } & Married & 698 & 96.7 \\
\hline & Divorced & 10 & 1.4 \\
\hline & Others & 14 & 1.9 \\
\hline \multirow{4}{*}{ Religion } & Traditional & 357 & 49.4 \\
\hline & Protestant & 214 & 29.6 \\
\hline & Orthodox & 135 & 18.7 \\
\hline & Others** & 16 & 2.2 \\
\hline \multirow{3}{*}{ Education of mothers or caregivers } & Secondary and above & 98 & 13.6 \\
\hline & Primary & 106 & 14.7 \\
\hline & Illiterate & 518 & 71.7 \\
\hline \multirow{4}{*}{ Occupation of mothers or caregivers } & Housewife & 235 & 32.5 \\
\hline & Farmer & 310 & 42.9 \\
\hline & Government employee & 66 & 9.1 \\
\hline & Other*** & 111 & 15.4 \\
\hline \multirow{3}{*}{ Age of fathers, $n=711$} & $18-24$ & 49 & 6.9 \\
\hline & $25-34$ & 326 & 45.9 \\
\hline & 35 and more & 336 & 47.2 \\
\hline \multirow{3}{*}{ Education of fathers } & Secondary and above & 125 & 17.6 \\
\hline & Primary & 117 & 16.5 \\
\hline & Illiterate & 469 & 66 \\
\hline \multirow{4}{*}{ Occupation of fathers } & Farmer & 246 & 34.6 \\
\hline & Livestock & 310 & 43.6 \\
\hline & Employee & 94 & 13.2 \\
\hline & Other**** & 61 & 8.6 \\
\hline \multirow{3}{*}{ Average income } & $<17$ USD & 311 & 43.1 \\
\hline & 17-33 USD & 134 & 18.6 \\
\hline & $>33$ USD & 277 & 38.4 \\
\hline \multirow{2}{*}{ Households own a television } & Yes & 82 & 11.4 \\
\hline & No & 640 & 88.6 \\
\hline \multirow{2}{*}{ Households have kitchen } & Yes & 315 & 43.6 \\
\hline & No & 407 & 56.4 \\
\hline \multirow{2}{*}{ Households send all the children of school age to school } & Yes & 378 & 52.4 \\
\hline & No & 344 & 47.6 \\
\hline
\end{tabular}

${ }^{*}$ Single, widowed, and separated; ${ }^{* *}$ Muslim and apostolic; ${ }^{* * *}$ daily laborer and jobless; USD, United States Dollar.

4.4. Determinants of Childhood Diarrhea. Among the addressed demographic, socioeconomic, and environmental factors, some showed association with childhood diarrhea. In crude analyses, rural residence of the household [COR: 1.65, 95\% CI: (1.09-2.50)], family size of more than four in the household [COR: 1.57, 95\% CI (1.06-2.32)], two or more under-five children in the household [COR: 1.27, 95\% CI (1.20-2.47)], illiteracy of the mother/caregiver [COR: 2.39, 95\% CI (1.29-4.43)], availability of television [COR: 3.13,
95\% CI (1.48-6.64)] and kitchen [COR: 1.62, 95\% CI (1.13-2.32)], availability of latrine facility [COR: $2.35,95 \%$ CI (1.66-3.34)], having faeces around the pit-hole or floor of latrine [COR: 4.45, 95\% CI (2.44-8.41)], improper kitchen waste disposal [COR: 2.48, 95\% CI (1.55-3.97)], unprotected drinking water source [COR: $2.07,95 \%$ CI (1.46-2.94)], and time of more than 30 minutes spent to fetch water [COR: $1.47,95 \%$ CI (1.03-2.08)] were found significantly associated with childhood diarrhea. Further, from child health and 
TABle 2: Environmental characteristics of the households in Benna Tsemay District, South Omo Zone, Southern Ethiopia, 01 January to 30 February, 2019.

\begin{tabular}{|c|c|c|c|}
\hline Variables $(n=722)$ & Response category & Frequency & Percentage $(\%)$ \\
\hline \multirow{4}{*}{ Housing floor material } & Mud & 631 & 87.4 \\
\hline & Wood & 67 & 9.3 \\
\hline & Cement & 14 & 1.9 \\
\hline & Other* & 10 & 1.4 \\
\hline \multirow{2}{*}{ Animals live in same house } & Yes & 187 & 25.9 \\
\hline & No & 535 & 74.1 \\
\hline \multirow{3}{*}{ Number of rooms } & One room & 474 & 65.7 \\
\hline & Two rooms & 93 & 12.9 \\
\hline & Three and above & 155 & 21.5 \\
\hline \multirow{2}{*}{ Latrine availability } & Yes & 438 & 60.7 \\
\hline & No & 284 & 39.3 \\
\hline \multirow{2}{*}{ Type of latrine $(n=438)$} & Improved & 10 & 2.3 \\
\hline & Traditional pit latrine & 428 & 97.7 \\
\hline \multirow{2}{*}{ Latrine ownership $(n=438)$} & Privately owned & 414 & 94.5 \\
\hline & Shared & 24 & 5.5 \\
\hline \multirow{2}{*}{ Faeces seen around the pit-hole or floor of latrine $(n=438)$} & Yes & 58 & 13.2 \\
\hline & No & 380 & 86.8 \\
\hline \multirow{2}{*}{ Latrine had pit-hole cover $(n=438)$} & Yes & 36 & 8.2 \\
\hline & No & 402 & 91.4 \\
\hline \multirow{2}{*}{ Faeces seen around house or in compound $(n=438)$} & Yes & 69 & 15.8 \\
\hline & No & 369 & 84.2 \\
\hline \multirow{2}{*}{ Hand wash facility } & Yes & 76 & 17.4 \\
\hline & No & 362 & 82.6 \\
\hline \multirow{2}{*}{ Hand wash facility had water then $(n=76)$} & Yes & 39 & 51.3 \\
\hline & No & 37 & 48.7 \\
\hline \multirow{2}{*}{ Hand washing facility contained soap or ash $(n=76)$} & Yes & 17 & 22.4 \\
\hline & No & 59 & 77.6 \\
\hline \multirow{4}{*}{ Place of disposal of child faeces } & Open field & 341 & 47.2 \\
\hline & Pit or burning & 69 & 9.6 \\
\hline & Latrine & 252 & 34.9 \\
\hline & Others** & 60 & 8.3 \\
\hline \multirow{2}{*}{ Waste disposal } & Proper disposal & 310 & 42.9 \\
\hline & Improper disposal & 412 & 57.1 \\
\hline \multirow{2}{*}{ Status of drinking water source } & Protected source & 438 & 60.7 \\
\hline & Unprotected source & 284 & 39.3 \\
\hline \multirow{2}{*}{ Time spent to fetch water } & Thirty minutes and less & 434 & 60.1 \\
\hline & More than thirty minutes & 288 & 39.9 \\
\hline \multirow{2}{*}{ Collected or storage water } & Yes & 234 & 32.4 \\
\hline & No & 488 & 67.6 \\
\hline \multirow{4}{*}{ Type of water collection and storage container $(n=234)$} & Pot & 7 & 3 \\
\hline & Plastic container & 45 & 19.2 \\
\hline & Iron container & 8 & 3.4 \\
\hline & Jerry cans & 174 & 74.4 \\
\hline \multirow{2}{*}{ Place water containers were kept } & On a table (raised place) & 46 & 19.7 \\
\hline & On the ground & 188 & 80.3 \\
\hline \multirow{2}{*}{ Cover for water container } & Yes & 224 & 95.7 \\
\hline & No & 10 & 4.3 \\
\hline \multirow{2}{*}{ Treat water at home } & Yes & 129 & 17.9 \\
\hline & No & 593 & 82.1 \\
\hline & Boiling & 30 & 23.4 \\
\hline Water treatment method & Filtering & 38 & 28.9 \\
\hline & Chemical & 61 & 47.7 \\
\hline
\end{tabular}

* Plastic sheet and stone; ${ }^{* *}$ garden, locally selected place. 
TABLE 3: Demographic and health characteristics of the indexed children in Benna Tsemay District, South Omo Zone, Southern Ethiopia, 01 January to 30 February, 2019.

\begin{tabular}{|c|c|c|c|}
\hline Variables & Response category & Frequency & Percentage (\%) \\
\hline \multirow{4}{*}{ Age of child (months) } & $0-5$ & 83 & 11.5 \\
\hline & $6-11$ & 108 & 15 \\
\hline & $12-23$ & 192 & 26.6 \\
\hline & $\geq 24-59$ & 339 & 47 \\
\hline \multirow{2}{*}{ Child sex } & Male & 336 & 46.5 \\
\hline & Female & 386 & 53.5 \\
\hline \multirow{2}{*}{ Place of delivery } & Home & 239 & 33.1 \\
\hline & Health facility & 483 & 66.9 \\
\hline \multirow{3}{*}{ Index child birth order } & First & 98 & 13.6 \\
\hline & Second & 127 & 17.6 \\
\hline & Third and above & 497 & 68.8 \\
\hline \multirow{2}{*}{ Mother or caretaker have diarrhea history in the last two weeks } & Yes & 24 & 3.3 \\
\hline & No & 698 & 96.7 \\
\hline \multirow{3}{*}{ Current breast feeding status } & Exclusive breast feeding & 101 & 14 \\
\hline & Partial breastfeeding & 415 & 57.5 \\
\hline & Not breastfeeding & 193 & 26.7 \\
\hline \multirow{3}{*}{ Time initiated for complementary feeding (months) $(n=621)$} & Before 6 months & 293 & 47.2 \\
\hline & At 6 months & 296 & 47.7 \\
\hline & After 6 months & 32 & 5.2 \\
\hline \multirow{5}{*}{ the child mostly takes food or fluid? } & Cow's milk & 255 & 41.1 \\
\hline & Powder milk & 19 & 3.1 \\
\hline & Gruel & 247 & 39.8 \\
\hline & Family food & 87 & 14 \\
\hline & Others* & 13 & 2.1 \\
\hline \multirow{4}{*}{ Method of feeding } & Hand & 225 & 36.2 \\
\hline & Cup and spoon & 280 & 45.1 \\
\hline & Bottle & 44 & 7.1 \\
\hline & Others** & 72 & 11.6 \\
\hline \multirow{2}{*}{ Separately prepare child food } & Yes & 463 & 74.6 \\
\hline & No & 158 & 25.4 \\
\hline \multirow{2}{*}{ Measles } & Yes & 521 & 72.2 \\
\hline & No & 201 & 27.8 \\
\hline \multirow{2}{*}{ Rotavirus vaccine } & Yes & 466 & 64.5 \\
\hline & No & 256 & 35.5 \\
\hline \multirow{2}{*}{ Have diarrhea in the last two weeks } & Yes & 170 & 23.5 \\
\hline & No & 552 & 76.5 \\
\hline
\end{tabular}

* Porridge and locally available food; ${ }^{* *}$ small dish and locally available material.

demographic determinants, the mother's or caretaker's history of diarrhea in the last two weeks [COR: 7.06, 95\% CI (2.96-16.8)], initiation of complementary feeding at 6 months [COR: $0.43,95 \%$ CI $(0.29-0.64)$ ], use of bottle to feed the child [COR: $0.50,95 \% \mathrm{CI}(0.28-0.91)$ ], and rotavirus vaccination status [COR: 2.53, 95\% CI (1.78-3.60)] were significantly associated with childhood diarrhea.

However, among all above determinants, after adjustment for other variables, seven variables were found significantly associated with under-five diarrhea. These included nonavailability of latrine, faeces seen around the pit hole or floor of latrine, improper kitchen waste disposal, unprotected drinking water source, mother's/caretaker's diarrhea history in the last two weeks, materials used for feeding the child (cup or spoon), and being unvaccinated for "rotavirus". Specifically, children from household with no latrine availability had 2.77 times higher odds of diarrhea relative to children in household with latrine facility (AOR: $2.77,95 \% \mathrm{CI}$ : 1.66-4.63). Faeces around the pit-hole or floor of latrine increased the odds of childhood diarrhea by about three-fold (AOR: 2.92, 95\% CI: 1.38-6.19). Children from households with improper kitchen waste disposal had 2.31 times higher odds of diarrhea compared with children from households with proper kitchen waste disposal (AOR: 2.31, 95\% CI: 1.26-4. 24), whereas children whose households consumed water from unprotected sources had nearly twice higher odds to develop diarrhea compared with children whose households consumed water from protected sources (AOR: 1.81, 95\% CI: 1.14-2.88). The odds of diarrhea were nearly seven-fold in children from households with maternal/caretaker's diarrhea history in the last two weeks compared with children from households where the mothers/caretakers had no diarrhea history in the last two weeks (AOR: 6.74, 95\% CI: 2.51-18.07). Further, children fed with cup and spoon had $40 \%$ lower odds of diarrhea than 
TABle 4: Demographic, socioeconomic, and child demographic health determinant of under-five diarrhea in Benna Tsemay District, South Omo Zone, Southern Ethiopia, 01 January to 30 February, 2019.

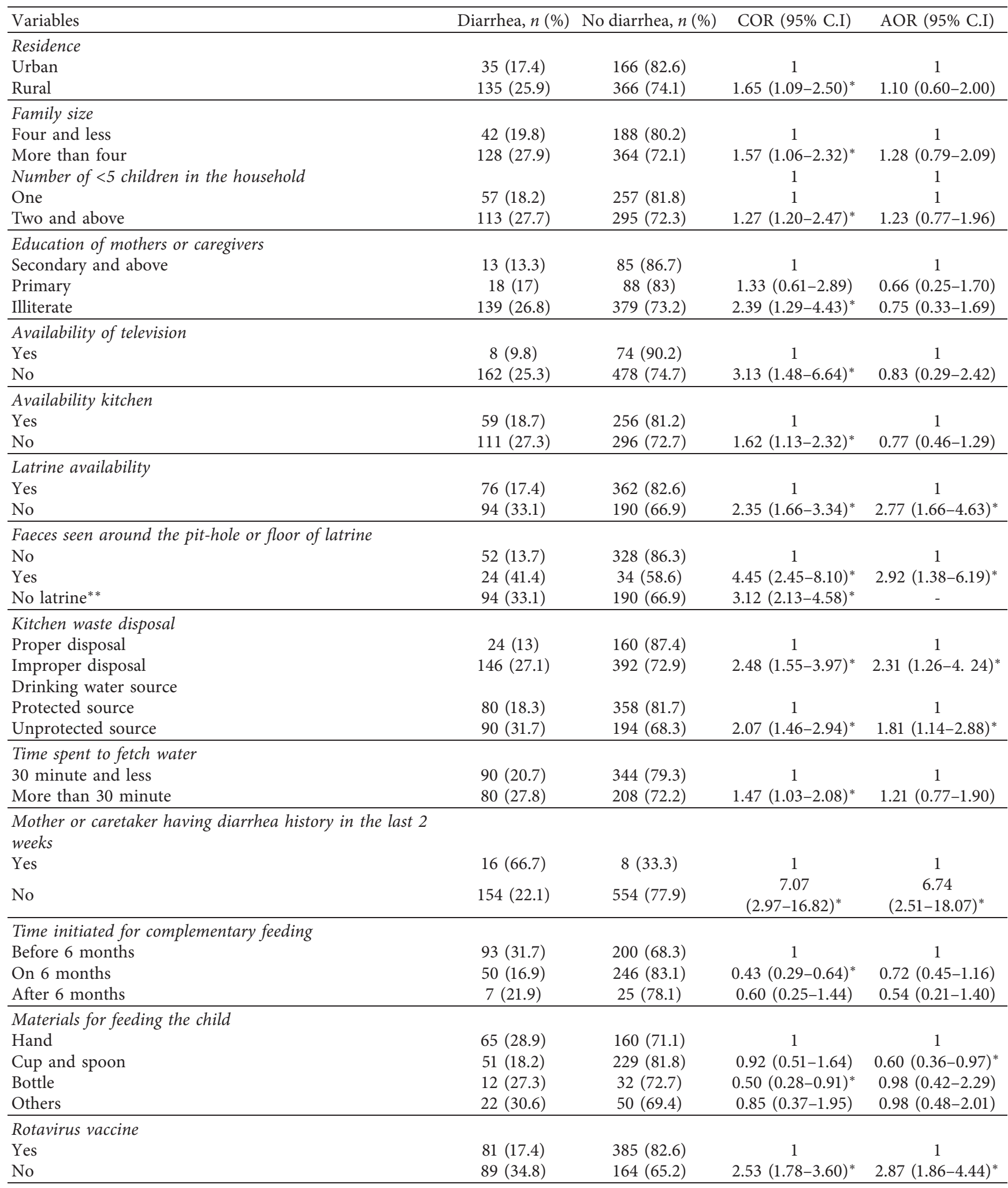

Note: AOR, adjusted odds ratio; COR, crude odds ratio. * Statistically significant at an alpha value of $0.05 .{ }^{* *}$ Due to redundancy with the variable "latrine availability," AOR for the third category of the variable "Faeces seen around the pit-hole or floor of latrine" cannot be computed. Hosmer and Lemeshow goodness-of-fit test: chi-squared $=8.54$; degree of freedom $=8 ; P$ value $=0.382$.

children fed by hand (AOR: 0.60, 95\% CI: 0.36-0.97), while the odds of having diarrhea was around three times higher among children unvaccinated for rotavirus than those vaccinated for rotavirus (AOR: 2.87, 95\% CI: 1.86-4.44) (Table 4). 


\section{Discussion}

The present study investigated the prevalence and socioeconomic and environmental risk factors of diarrheal disease among children under-five years in southern Ethiopia. The two-week period prevalence of childhood diarrheal disease in this study was $23.5 \%$ with $95 \%$ CI: $(20.4,26.6)$. Factors that were statistically significant predictors of childhood diarrhea were nonavailability of latrine, faeces seen around the pit hole or floor of latrine, improper kitchen waste disposal, unprotected drinking water source, mother's or caretaker's diarrhea history in the last two weeks, materials used for feeding the child (cup or spoon), and being unvaccinated for rotavirus.

The prevalence of diarrhea in under-five children in this study was in line with a study conducted in Kersa District, Eastern Ethiopia (22.5\%), Jabithennan District, Northwest Ethiopia (21.5\%), Yaya Gulele district (22.4\%), Hadaleala District, Afar Region (26.1\%) [10, 18-20] and also other studies conducted in Cameroon (23.8\%), Guinea-Bissau (22.3\%), and India-Kashmir (25.2\%) [21-23] and relatively low compared with studies performed in Enderta Woreda, Northern Ethiopia (35.6\%), and Arba Minch District, Southern Ethiopia (30.5\%) [14, 24]. But this two-week period prevalence of diarrhea is high compared with the study reported nationally from EDHS in 2016, which is $12 \%$ [8] and studies conducted in Jimma Zone, South West Ethiopia (14.9\%), Laelay Michew District of Tigray Region, North Ethiopia (17.7\%), Wolitta Zone, Southern Ethiopia (11\%), and Farta District, North West Ethiopia (16.7\%) [16, 25-27]. The possible justification for this difference might be geographical, sociocultural, and economic differences. Especially, the higher prevalence of diarrhea in this study relative to several previous studies $[16,25-27]$ could be attributable to the low socioeconomic development in the pastoralist community addressed by the present study compared with other parts of the country and use of unprotected water source such as rivers, streams, and pools, which are prone to contamination.

The excreta of all infected people are dangerous. It is impossible to know who is infected and so it is important to dispose safely all excreta in latrine. In this study, children from households without latrine facilities had more than twice higher odds to develop diarrhea compared with children from households with latrine facilities. This finding was similar with that of the other studies $[4,11,20,28]$.

In this study, faeces seen around the pit-hole or floor of latrine was another factor associated with under-five diarrheal disease. Children from households where there were faeces seen around the pit-hole or floor of latrine had almost three times higher odds of diarrhea than those children from the households where faeces were not observed around the pit-hole or floor of latrine. This finding is consistent with that of the other studies $[7,21]$. This might be due to the fact that during latrine visit, faeces around the pit-hole or floor of latrines create opportunity for direct contact with excreta. Furthermore, poorly managed human excreta may pollute drinking water sources and different food items and creates favorable conditions for vector breeding which could facilitate a wide spread of diarrhea.
Children from households who use unprotected water sources had higher odds to experience diarrhea compared with children from households who use protected water sources, which is similar with that of studies performed in Jigjiga District, Somali Region, Eastern Ethiopia [11] and in Medebay Zana District, Northwest Tigray, Ethiopia, Bahir Dar Zuria District, and Hadaleala District $[9,20,28]$. This could be because unprotected water sources are highly likely to be polluted and to predispose children for diarrhea.

Children from the households with mothers/caretakers who had diarrheal history in the last two weeks had more probability to have diarrhea compared with the children from households with mother or caretakers who had no diarrhea history in the last two weeks. The findings of this study was almost similar with the findings of studies conducted in Mecha District, West Gojam, Ethiopia; Jijjiga District, Somali Region; and Zana District, Northwest Tigray $[9,11,28,29]$. Mothers in the study area often had close and direct contact with their children as they assume the primary responsibility for taking care of their children. This could lead to direct transmission of diarrheal disease from mothers to children.

This study also revealed that a rotavirus vaccination status was significantly associated with childhood diarrhea. Children who were not vaccinated for rotavirus had almost three times more odds to develop diarrhea than children vaccinated for rotavirus. It agreed with the finding reported from Farta Wereda, Northwest Ethiopia [28]. Rotavirus is known to cause more than a fifth of diarrhea hospitalizations among children globally [30]. This implies that rotavirus vaccination could be one of the ways to prevent diarrheal disease.

Children from household who practice improper kitchen waste disposal had 2.3 higher odds of diarrhea compared with children from household with proper kitchen waste disposal. This finding was consistent with findings from elsewhere such as Sheko district rural community, Southwest Ethiopia [31], Eastern Ethiopia [18], Jigjiga District, Somali Region, Eastern Ethiopia [11], Dale District, Sidama zone, Southern Ethiopia [32], and Jamma district, South Wello zone, Northeast Ethiopia [33]. This could be due to the fact that improper waste disposal creates easy access for vectors and rodents which will facilitate the transmission of diarrhea by contaminating foods, drinks, and household utensils. Besides, small children may come in direct contact with the waste and hence will be predisposed to diarrhea.

In the present study, children whose mothers/caretakers practice cup and spoon feeding had $40 \%$ lesser odds to develop diarrhea compared with children whose mothers practice feeding by hand. This evidence corroborated results from Northwest Ethiopia [10], and Southern Ethiopia [34]. The probable reason might be that cup and spoon feeding prevents contamination and such materials can be easily cleaned.

The present study has limitations. The risk of childhood diarrhea varies by season. Hence, it was difficult to detect seasonal variations in diarrheal morbidity. Besides, since this study was done in the dry season, it might underestimate the magnitude of diarrhea. Recall bias of diarrhea episodes and vaccination status of the children is also possible. Consequently, while bias in reporting diarrhea history could 
underestimate or overestimate the magnitude of diarrhea, bias in reporting vaccination status could also bias the association between diarrhea and vaccinations status.

\section{Conclusions}

In this study, nearly one-fourth of children had diarrheal illness in the preceding two weeks. Nonavailability of latrine, faeces seen around the pit-hole or floor of latrine, improper kitchen waste disposal, unprotected drinking water source, mothers' or caretakers' diarrhea history in the last two weeks, materials used for feeding the child (cup and spoon), and being unvaccinated for "rotavirus" were statistically significant predictors of diarrhea among under-five children. The health office is advised to conduct sustainable health education programs that emphasize the risk of open defecation, waste disposal mechanisms, and child feeding practices and also it needs to strengthen "rotavirus" vaccination activities. The district administration and partners' shall work towards on strengthening environmental health packages for improving drinking water sources and sanitation to tackle childhood diarrhea.

\section{Data Availability}

The orginal data used to support the findings of this study are available in the hand of authors.

\section{Conflicts of Interest}

The authors declare that they have no conflicts of interest.

\section{Acknowledgments}

The financial support to conduct this study was provided by the College of Medicine and Health Sciences (CMHS) of Hawassa University. CMHS has no role in the manuscript writing, editing, approval, or decision to publish. The authors would like to appreciate mothers/care takers who participated in this study. The data collectors also deserve thanks. Finally, the authors express gratitude to South Omo Zone Health Department and Benna Tsemay District Health Office for their support during the field work.

\section{References}

[1] B. V. Hung, "The most common causes of and risk factors for diarrhea among children less than five years of age admitted to Dong Anh Hospital, Hanoi, Northern Vietnam," Master's thesis, University of Oslo, Oslo, Norway, 2006.

[2] Z. K. Mandefro, "An investigation of environmental factors impacting on diarrhoea in children under five years old in Akakikality Sub City, Addis Ababa, Ethiopia," Master's thesis, University of South Africa, Pretoria, South Africa, 2014.

[3] The United Nations Children's Fund (UNICEF)/World Health Organization (WHO), Diarrhoea: Why Children Are Still Dying and what Can Be Done, UNICEF/WHO, Geneva, Switzerland, 2009.

[4] W. Godana and B. Mengistie, "Determinants of acute diarrhoea among children under five years of age in Derashe
District, Southern Ethiopia," Rural and Remote Health, vol. 13, no. 3, p. 2329, 2013.

[5] United Nations Children's Fund (UNICEF), Diarrhoeal Disease, UNICEF, New York, NY, USA, 2019, https://data. unicef.org/topic/child-health/diarrhoeal-disease/.

[6] World Health Organization (WHO), Diarrhoeal Disease, WHO, Geneva, Switzerland, 2017, https://www.who.int/ news-room/fact-sheets/detail/diarrhoeal-disease.

[7] G. Regassa, W. Birke, B. Deboch, and T. Belachew, "Environmental determinants of diarrhea among under-five children in Nekemte town, western Ethiopia," Ethiopian Journal of Health Sciences, vol. 18, no. 2, pp. 39-45, 2008.

[8] Central Statistical Agency (CSA) [Ethiopia] and ICF, Ethiopia Demographic and Health Survey 2016. Addis Ababa, Ethiopia, and Rockville, CSA and ICF, Rockville, MD, USA, 2016.

[9] D. T. Asnakew, M. G. Teklu, and S. A. Woreta, "Prevalence of diarrhea among under-five children in health extension model households in Bahir Dar Zuria district, north-western Ethiopia," Edorium Journal of Public Health, vol. 4, pp. 1-9, 2017.

[10] Z. A. Anteneh, K. Andargie, and M. Tarekegn, "Prevalence and determinants of acute diarrhea among children younger than five years old in Jabithennan District, Northwest Ethiopia, 2014," BMC Public Health, vol. 17, no. 1, p. 99, 2017.

[11] A. Hashi, A. Kumie, and J. Gasana, "Prevalence of diarrhoea and associated factors among under-five children in Jigjiga District, Somali Region, Eastern Ethiopia," Open Journal of Preventive Medicine, vol. 06, no. 10, pp. 233-246, 2016.

[12] Benna Tsemay District Health Office, Annual Report, Keyiafer: Benna Tsemay District Health Office, Bena Tsemay, Ethiopia, 2017.

[13] Benna Tsemay District Mine and Water Office, Annual Report, Keyiafer: Benna Tsemay District Mine and Water Office, Bena Tsemay, Ethiopia, 2017.

[14] S. Mohammed and D. Tamiru, "The burden of diarrheal diseases among children under five years of age in Arba Minch District, Southern Ethiopia and associated risk factors: a Cross-Sectional Study," International Scholarly Research Notices, vol. 2014, Article ID 654901, 6 pages, 2014.

[15] R. Siraj, "Determinants of diarrhea among children of underfive years of age in Haramaya District, Eastern Ethiopia," Master's thesis, Haramaya University, Oromia, Ethiopia, 2015.

[16] T. Angesom, "Prevalence and associated factors of acute diarrhea among under-five children in Laelay Maychew district, Tigray Region, Ethiopia," Master's thesis, Addis Ababa University, Addis Ababa, Ethiopia, 2015.

[17] Central Statistical Agency [Ethiopia] and ICF International, Ethiopia Demographic and Health Survey 2011. Addis Ababa, Ethiopia and Calverton, Central Statistical Agency and ICF International, Calverton, MD, USA, 2012.

[18] B. Mengistie, Y. Berhane, and A. Worku, "Prevalence of diarrhea and associated risk factors among children under-five years of age in Eastern Ethiopia: a cross-sectional study," Open Journal of Preventive Medicine, vol. 3, no. 7, pp. 446-453, 2013.

[19] M. Degebasa, Z. Dawit, M. Marama, and M. T. Marama, "Diarrheal status and associated factors in under five years old children in relation to implemented and unimplemented community-led total sanitation and hygiene in Yaya Gulele in 2017," Pediatric Health, Medicine and Therapeutics, vol. 9, pp. 109-121, 2018. 
[20] B. D. Bitew, W. Woldu, and Z. Gizaw, "Childhood diarrheal morbidity and sanitation predictors in a nomadic community," Italian Journal of Pediatrics, vol. 43, p. 91, 2017.

[21] A. Tambe, L. Nzefa, and N. Nicoline, "Childhood diarrhea determinants in sub-saharan africa: a cross sectional study of Tiko-Cameroon," Challenges, vol. 6, no. 2, pp. 229-243, 2015.

[22] K. Mølbak, H. Jensen, L. Ingholt, and P. Aaby, "Risk factors for diarrheal disease incidence in early childhood: a community cohort study from Guinea-Bissau," American Journal of Epidemiology, vol. 146, no. 3, pp. 273-282, 1997.

[23] S. F. Ahmed, A. Farheen, A. Muzaffar, and G. M. Mattoo, "Prevalence of diarrhoeal disease, its seasonal and age variation in under-fives in Kashmir, India," International Journal of Health Sciences, vol. 2, no. 2, pp. 126-133, 2008.

[24] H. Berhe, A. Mihret, and G. Yitayih, "Prevalence of diarrhea and associated factors among children under-five years of age in Enderta Woreda, Tigray, Northern Ethiopia, 2014," International Journal of Therapeutic Applications, vol. 31, pp. 32-37, 2016.

[25] L. F. Kasee, O. S. Merrom, and H. Y. Hassa, "Assessment of the prevalence of diarrheal disease under-five children serbo town, Jimma Zone South West Ethiopia," Clinics in Mother and Child Health, vol. 15, no. 1, p. 1000280, 2018.

[26] K. A. Alambo, "The prevalence of diarrheal disease in under five children and associated risk factors in Wolitta Soddo Town, Southern Ethiopia ABC research alert," vol. 3, no. 2, pp. 12-22, 2015.

[27] G. Gedamu, A. Kumie, and D. Haftu, "Maginitude and associated factors of diarrhea among under five children in Farta Wereda, North West Ethiopia," Quality in Primay Care, vol. 25, no. 4, pp. 199-207, 2017.

[28] K. F. Asfaha, F. A. Tesfamichael, G. K. Fisseha et al., "Determinants of childhood diarrhea in Medebay Zana District, Northwest Tigray, Ethiopia: a community based unmatched case-control study," BMC Pediatrics, vol. 18 , no. 1, p. 120, 2018.

[29] M. Dessalegn, A. Kumie, and W. Tefera, "Predictors of underfive childhood diarrhea: Mecha District, West Gojjam, Ethiopia," Ethiopian Journal of Health Development, vol. 25, no. 3, pp. 192-200, 2014.

[30] U. D. Parashar, C. J. Gibson, J. S. Bresee, and R. I. Glass, "Rotavirus and severe childhood diarrhea," Emerging Infectious Diseases, vol. 12, no. 2, pp. 304-306, 2006.

[31] T. Gebru, M. Taha, and W. Kassahun, "Risk factors of diarrhoeal disease in under-five children among health extension model and non-model families in Sheko district rural community, Southwest Ethiopia: comparative cross-sectional study," BMC Public Health, vol. 1, p. 395, 2014.

[32] B. Melese, W. Paulos, F. H. Astawesegn, and T. B. Gelgelu, "Prevalence of diarrheal diseases and associated factors among under-five children in Dale District, Sidama Zone, Southern Ethiopia: a cross-sectional study," BMC Public Health, vol. 19, no. 1, p. 1235, 2019.

[33] G. Y. Workie, T. Y. Akalu, and A. G. Baraki, "Environmental factors affecting childhood diarrheal disease among underfive children in Jamma District, South Wello Zone, Northeast Ethiopia," BMC Infection Diseases, vol. 19, no. 1, p. 804, 2019.

[34] D. Gashaw, K. Woldemichael, T. Shewanew, and K. Yitbarek, "What factors aggravate prevalence of diarrhea among infants of 7-12 months in Southern Ethiopia?" Quality in Primary Care, vol. 25, no. 5, pp. 321-325, 2017. 